\title{
Understanding Credit Derivatives and their Potential to Synthesize Riskless Assets
}

\author{
Antulio N. Bomfim* \\ Federal Reserve Board
}

July 11, 2001

\begin{abstract}
The credit derivatives market is emerging as a potentially important new development that may help shape the overall financial markets in the years to come. In this paper, I provide a brief overview of the credit derivatives market and assess its future potential in the creation of private-sector instruments that are virtually free of default risk, and, thus, may be appealing to investors who currently favor the safety of U.S. Treasury securities.
\end{abstract}

JEL Classification: G13, G20

Keywords: credit default swaps, risk, asset swaps, financial engineering, synthetic CDOs

* Monetary and Financial Market Analysis, Mail Stop 74, Division of Monetary Affairs, Federal Reserve Board, Washington, DC, 20551; Email: abomfim@frb.gov, Fax: (202) 452-2301, Tel.: (202) 736-5619. I thank Thomas Benison, Andrew Palmer, and James Ballentine for helpful conversations and for providing the data used in this paper. I am also grateful to James Clouse, Darrel Cohen, William English, Michael Gibson, and Vincent Reinhart for comments and to Jeffrey Slone for excellent research assistance. The opinions expressed in this paper are not necessarily shared by the Board of Governors of the Federal Reserve System or any members of its staff. 


\section{Introduction}

Credit derivatives are financial contracts that allow the transfer of credit risk from one market participant to another, potentially facilitating greater efficiency in the pricing and distribution of credit risk among financial market participants. The following example illustrates the simplest and most com-

mon form of a credit derivative, the credit default swap: The holder of a debt security issued by XYZ Corp. enters into a contract with a derivatives dealer whereby she will make periodic payments to the dealer in exchange for a lump sum payment in the event of default by XYZ Corp. during the term of the derivatives contract. As a result of entering into such a contract, the investor has effectively transfered the risk associated with default by XYZ Corp. to the dealer. In market parlance, the corporate bond investor in this example is the buyer of protection, the dealer is the protection seller, and the issuer of the corporate bond is called the reference entity.

In this note, I discuss the market for credit derivatives, highlighting its rapid growth in recent years and where the market is likely to go in the future. I also discuss methods for pricing credit derivatives and illustrate simple strategies involving the use of credit derivatives to synthesize an asset with a credit risk profile that, at least in principle, resembles that of Treasury securities. Once the credit derivatives market reaches its full maturity, such strategies could potentially be appealing to buy-and-hold investors who are attracted to the safety of U.S. Treasury securities, but who are facing the prospect of a shrinking stock of federal government debt. 


\section{Market Overview}

Credit derivatives are negotiated over the counter in a market that has grown spectacularly in recent years. ${ }^{1}$ Still, the market is small relative to the overall derivatives market, and it has not yet reached the liquidity, transparency, standardization, and widespread market participation of more mature markets. For instance, according to Bank Call Report data, credit derivatives represented only a little more than one percent of the total notional amount of derivatives at U.S. commercial banks at the end of 2000, although the credit derivatives' share of the total has risen substantially in recent years. As shown in Figure 1, notional amounts outstanding in credit derivatives at U.S. commercial banks have increased from around $\$ 50$ billion in late 1997 to over $\$ 400$ billion in the fourth quarter of last year.

The market is developing outside the United States as well, and, according to a survey by the British Bankers' Association (BBA), the global credit derivatives market is estimated to be at least twice as big as the U.S. market (British Bankers' Association, 2000). From virtually nonexistent in the early 1990s, the global credit derivatives market comprises nearly $\$ 1$ trillion dollars in notional amounts outstanding today and is projected to grow to $\$ 1.5$ trillion by 2002 . It should be noted, however, that the exact size of both the U.S. and global credit derivatives market is difficult to estimate given the potential for overcounting when contracts involve more than one reporting market participant and that notional amounts outstanding considerably overstate the net exposure associated with those contracts.

\footnotetext{
${ }^{1}$ Extensive discussions of credit derivatives and the evolution of the market can be found in J.P. Morgan (1999), O'Kane (2001), Rule (2001), and Tavakoli (1998).
} 


\subsection{Uses of Credit Derivatives}

As with any other derivative instrument, credit derivatives can be used either to take on more risk or to avoid (hedge) it. As noted earlier, a market participant who is exposed to the credit risk of a given corporation can hedge such an exposure by buying protection in the credit derivatives market. Likewise, an investor may be willing to take on that credit risk by selling protection and thus enhance the expected return on his portfolio.

Credit derivatives can be used to create positions that would otherwise not easily be established in the cash market. For instance, consider an investor who has a negative view on the future quality of a given corporation. One strategy for such an investor would be to short the bonds issued by the corporation, but the corporate repo market and other mechanisms for tak-

ing short positions in corporates are not well developed for most individual corporate issuers. By buying protection in the credit default swap (a form of a credit derivative), the investor essentially mimics the cash flows of a short position in the corporation's debt. Should the corporation default, the investor is able to buy the defaulted debt for its recovery value in the open market and sell it to its credit derivatives counterparty for its face value. (Credit default swaps are discussed in section 3.)

\subsection{Market Participants}

By far, the main users of credit derivatives are large banks, followed by securities firms and insurance companies. While banks and securities firms act both as sellers and buyers of protection, insurance companies, which have reportedly increased their market participation substantially in recent years, are primarily protection sellers, presumably using their expertise at evaluating risk. Non-financial corporations have reportedly also increasingly 
come to the market, but primarily to buy protection to hedge their exposure in vendor financing deals. Hedge funds are also relatively active participants, arbitraging perceived mispricings between the cash and derivatives market and thus participating in both sides of the market. Other participants include pension funds and mutual funds, but their participation in the market is very small.

Banks use credit derivatives both to diversify their credit risk exposures and to free up capital from regulatory constraints. As an example, consider a bank that wants to diminish its exposure to a given client, but does not want to incur the costs of transferring loans made to that client to another bank. (Part of these costs might be a potential deterioration in the bank's relationship with the client.) The bank can, without having to notify its client, buy protection against default by the client in the credit derivatives market: Even though the loans remain on the bank's books, the associated credit risk has been transferred to the bank's counterparty in the credit derivative contract.

The above example can also be used to illustrate banks' usage of credit derivatives to reduce their regulatory capital requirements. Under current Basle standards, for a corporate borrower, the bank is generally required to hold 8 percent of its exposure as a regulatory capital reserve. However, if its credit derivatives counterparty happens to be a bank located in an OECD country, and the bank can demonstrate that the credit risk associated with the loans has been effectively transfered to the OECD bank, then the bank's regulatory capital charge falls from 8 percent to 1.6 percent. 


\section{Types of Credit Derivatives}

In a broad sense, credit derivatives can be classed in two main groups: Singlename instruments are those that involve protection against default by a single reference entity, such as the credit default swap outlined in the introduction. Multi-name credit derivatives are contracts that are contingent on default events in a pool of reference units. As such, multi-name instruments allow investors and issuers to transfer the credit risk associated with a portfolio of risky securities, as opposed to dealing with each security in the portfolio separately. Single-name instruments account for the majority of the credit derivatives market, but the use of multi-name products has grown substantially in recent years (British Bankers' Association, 2000).

\subsection{Single-Name Credit Derivatives}

Credit Default Swaps. The credit default swap (CDS) is the most common form of a single-name instrument. Indeed, the CDS is the most common credit derivative, serving as the building block for many complex multi-name products. According to the British Bankers' Association (2000), CDSs account for about 40 percent of the global derivatives market in terms of notional amounts outstanding, although anecdotal accounts by dealers suggest that CDSs account for a much larger share of the total activity in the credit derivatives market. ${ }^{2}$

In a vanilla CDS, the protection buyer agrees to make periodic payments (the swap "spread" or premium) over a predetermined number of years (the maturity of the CDS) to the protection seller in exchange for a payment in the event of default by a third party (the reference entity). Typically, CDS

\footnotetext{
${ }^{2}$ CDSs are much more common than multi-name credit derivatives such as synthetic collateralized debt obligations, but the latter have substantially larger notional amounts.
} 
premiums are paid quarterly, and the most common maturities are 3, 5, and 10 years, with the five-year maturity being especially active (O'Kane, 2001). The premium is set as a percentage of the total amount of protection bought (the notional amount). For instance, the parties might agree that the CDS will have a notional amount of $\$ 100$ million: If the annualized swap spread is 40 basis points, then the protection buyer will pay $\$ 100,000$ every quarter to the protection buyer. If no default event occurs during the life of the CDS, the protection seller simply pockets the premium payments. Should a default event occur, however, the protection seller becomes liable for the difference between the face value of the debt obligations issued by the reference entity and their recovery value.

In the event of default, CDSs can be settled physically or in cash, with the settlement choice determined up front when entering the contract. In a physically settled swap, the protection buyer has the right to sell the defaulted assets to the protection seller for their face value. In a cash settled swap, the counterparties agree to poll market participants to determine the recovery value of the defaulted assets, and the protection seller is liable for the difference between face and recovery values. By far, the majority of CDS in the United States are physically settled.

The adoption of standardized documentation for credit default swaps has played an important role in the development and greater liquidity of this segment of the credit derivatives market. Similar to the interest rate swap market, the use of master agreements sponsored by the International Swaps and Derivatives Association (ISDA) is now a common market practice, significantly reducing legal risk and setup and negotiation costs. Nonetheless, some ambiguity still exists in the standardized documentation as to what constitutes the legal definition of a default event, especially the treatment of debt restructuring by reference entities. 
Credit default swaps are the most liquid type of credit derivative, and, although market prices for such contracts are still not widely disseminated, some dealers have started to post daily CDS spreads for a number of reference entities. In addition to being indicative of the growing liquidity of CDSs, the existence of such quotes suggests that prices in this market could potentially become useful indicators of investors' perceptions of credit risk and their willingness to bear it. For example, Figure 2 shows market quotes for credit default swap premiums for Ford Motor Credit and IBM, reportedly two of the reference entities that are viewed as "benchmarks" in the credit default swap market. The data show that the cost of buying protection against default even by these two highly rated companies rose appreciably in October 2000, at the same time that uncertainty about the overall economic outlook was increasing. On net, these premiums had retraced only part of that increase during the first few months of 2001. (CDS spreads for most reference entities followed a similar pattern in late 2000 and early 2001.) The data also show that the cost of buying default insurance on Ford Motor Credit, which is rated A by Standard and Poors, is about twice as large as that for IBM, which is rated $\mathrm{A}+$.

The series shown in Figure 2 are mid-market quotes. Bid-asked spreads in the CDS market can be as narrow as 5 basis points for more commonly negotiated contracts, which are those written on large financial and nonfinancial corporations. Spreads can be appreciably wider for lower-rated reference entities that are seen as headed for financial distress.

Other single-name credit derivatives. The asset swap is another example of a financial contract that is often classified by market participants as a credit derivative. Asset swaps allow investors to take pure credit positions regarding a particular issuer. In an asset swap, an investor can buy a fixedrate liability issued by a reference entity and simultaneously enter an interest 
rate swap where the fixed rate and payment dates exactly match those of the fixed-rate liability. The floating rate in such a swap is conventionally quoted as a spread over short-term LIBOR, called the asset swap spread. The end result of an asset swap is a synthetic floating-rate liability issued by the reference entity, which means that the investor effectively transferred the interest rate (market) risk of the fixed-rate liability to its asset swap counterparty, retaining only the credit risk component. According to the $\mathrm{BBA}$, in terms of notional amounts outstanding, around 12 percent of the credit derivatives market corresponds to asset swaps.

Other single-name credit derivatives include credit spread options and total return swaps. A credit spread option is a derivatives contract where the payoff is based on the credit spread of the reference entity relative to some strike level. As with other options, the contract specifies the strike level and maturity of the option, as well as whether it is a call or put option.

In a total return swap, an investor (the total return receiver) enters into a derivatives contract whereby she will receive all the cash flows associated with a given reference asset without actually ever owning the asset. In exchange for such cash flows, the investor makes periodic payments, conventionally quoted as a spread over short-term LIBOR, to its derivatives counterparty (the total return payer). Should the issuer of the reference asset default during the term of the total return swap, the investor sustains the associated loss, otherwise, at maturity of the total return swap, the total return payer pays the difference between the prevailing price of the reference asset and its price at the inception date of the contract. Total return swaps are discussed in detail by Tavakoli (1998), who also addresses other types of credit derivatives. 


\subsection{Multi-Name Credit Derivatives}

Rather than being based on the credit risk characteristics of a single debtor, a credit derivative can be written on a portfolio or "basket" of assets, such as a portfolio of business loans. The simplest form of such derivatives is called a basket swap. A common example of a basket swap is a first-todefault basket. In such a contract, the payment by the protection seller is triggered by a default event by any of the reference entities included in the portfolio. Effectively, if the protection buyer is long the portfolio, he limits his exposure to credit risk by transferring some of that risk to the protection seller. Second- and third-to-default baskets are similarly defined.

Alternatively, a multi-name credit derivative may be set up as a portfolio default swap, whereby the transfer of risk is specified not in terms of defaults by individual reference entities represented in the portfolio but rather in terms of the size of the default-related loss in the overall portfolio. For instance, in a portfolio default swap with a "first-loss tranche" of, say, 10 percent, investors in that tranche (first-loss protection sellers) are exposed to however many individual defaults are necessary to lead to a 10 percent loss in the overall portfolio. Second- and third-loss portfolio default swaps are defined similarly.

Portfolio default swaps can be thought of as the building blocks for synthetic collateralized debt obligations (CDOs). While a simple credit default swap allows a bank to synthesize the sale of a loan, using a synthetic CDO a bank can transfer part of the credit risk in an entire portfolio of loans without having to incur the costs of transferring the loans themselves off its balance sheet. As in a conventional CDO, the cash flow of a synthetic $\mathrm{CDO}$ is directed to various tranches to suit the risk appetites of different investors. Thus, while investors in the most senior tranches face very low default risk, those in the first-loss (equity) tranche will be the first to absorb 
any default-related losses in the portfolio.

\subsection{Credit-Linked Notes}

Certain investors are prevented from entering into derivatives contracts, either by law or by internal investment policies. Credit-linked notes allow such investors to derive some of the benefits of credit derivatives, both single- and multi-name.

Credit-linked notes are regular debt obligations with an embedded credit derivative. They can be issued either directly by a corporation or bank or by highly rated special purpose vehicles created by dealers. The coupon payments made by a CLN effectively transfer the cash flow of a credit derivatives contract to individual investors.

Credit-linked notes are best understood by a simple example: ABC Investments would like to take on the risk associated with the debt of XYZ Corp., but all of XYZ's debt is composed of bank loans and ABC Investments cannot simply sell protection in a credit default swap because its investment policy prevents it from entering into a derivatives contract. Let us assume that the size of ABC Investments' desired exposure to XYZ Corp. is $\$ 100$ million. One way of gaining the desired exposure to XYZ's debt is for ABC Investments to purchase $\$ 100$ million in credit-linked notes that reference XYZ Corp. The issuer of the notes may take ABC Investments' $\$ 100$ million and buy highly-rated debt obligations to serve as collateral for its CLN liability toward ABC Investments. At the same time, the CLN issuer enters into a credit default swap with a third party, selling protection against a default by XYZ Corp. From that point on, the CLN issuer will simply pass through the cash flows associated with the credit default swap - net of administrative fees - to ABC investments. In the event of default by XYZ Corp., the CLN issuer will pay its default swap counterparty and the credit-linked note ter- 
minates with $\mathrm{ABC}$ Investments receiving only the recovery value of XYZ's defaulted debt. If no default occurs, ABC Investments will continue to receive the coupon payments associated with the credit-linked note until its maturity date, at which point it will also receive its principal back. It should then be clear that a credit-linked note is simply a funded way of entering into a credit derivatives contract. (Indeed, CLNs can be written based on more complex credit derivatives, such as a synthetic CDOs.)

\section{The Pricing of Credit Derivatives}

In a frictionless financial market, the pricing of a credit derivative depends only on the economic fundamentals of the reference entity(ies) and the derivative counterparties. In practice, however, other factors, such as liquidity of the cash and derivative markets in the corporate debt market, undeveloped repo markets, and market segmentation also affect derivatives prices, driving a wedge between the theoretical prices suggested by fundamentals and observed market prices.

\subsection{Fundamental Factors}

To keep things simple, I start by assuming that financial markets operate without frictions. In addition, I shall focus on the determinants of credit default swap spreads, although many of the general points made below generalize to more complex credit derivatives.

The pricing of credit default swaps is fundamentally linked to four main factors: (i) the credit risk of the reference entity, (ii) the expected recovery rates associated with the reference entity and the protection seller, (iii) the credit risk of the protection seller, and (iv) the default correlation between the reference entity and the protection seller. The importance of the first 
two factors is clear: The greater the likelihood of default by the reference entity and, assuming that the protection seller does not default on its CDS obligation, the lower the post-default value of the defaulted debt-which the protection provider buys for its par value in the event of default - the more expensive the protection.

Items (iii) and (iv) highlight a significant factor for purchasers of protection in the credit default swaps market: the credit quality of the protection seller. Indeed, regarding its credit derivatives counterparty, the protection buyer is subject to two types of risk: Should the protection seller default before the reference entity, the protection buyer is exposed to "replacement risk" or the risk that the price of default insurance on the reference entity might have risen since the original default swap was negotiated. The protection buyer's greatest loss, however, would occur when both the protection seller and the reference entity default at the same time, but such a joint event is typically much less likely than a default by the protection seller alone, especially when the default correlation between the reference entity and the protection seller is low. As is the case with other derivatives, the effect of counterparty credit risk in the pricing of credit default swaps is reduced by the use of netting arrangements and collateral agreements among counterparties, although the latter is more prevalent in the interdealer market.

\subsection{An Example: Pricing a Credit Default Swap}

It typically costs nothing to enter into a CDS because the quoted spread is such that the CDS has zero market value when it is first entered into. The question then is how to find the value of such a spread. I shall outline two approaches to pricing a CDS. The first is relatively model-free and based on simple arbitrage arguments. The second relies on credit risk models. In describing both approaches, I abstract from discussing how the credit 
quality of the protection seller is factored into the pricing of a CDS, implicitly assuming that effective measures to mitigate counterparty credit risk have been put in place. ${ }^{3}$

Pricing a CDS by static replication. A simple approach to (approximately) price a CDS that does not require the use of any model is to set up a portfolio with simple securities that replicate the cash flows of the CDS. In the absence of arbitrage opportunities, the cost of setting up the replicating portfolio gives the price of the CDS.

Example 1: Let us start with a very stylized example. Consider an investor who is offered the choice of either of two portfolios

- a long position in a risky floater yielding $R^{f}+S$ combined with a short position in a riskless floater yielding $R^{f}$;

- a short position (protection seller) in a CDS written on the risky floater.

We assume that both floaters have the same maturity, coupon dates, and face values $(\$ 1)$, and that they sell at par immediately after their coupon payment dates. To keep things even simpler, let us postulate further that the recovery rate on the risky floater is zero and that default can only occur immediately after the coupon payment dates. ${ }^{4}$

What are the cash flows associated with each portfolio? For as long as the issuer of the risky floater does not default, the first portfolio yields $S$ every period. As for the second portfolio, the CDS has a cash flow of $P$ every period, where $P$ is the CDS spread.

In the event of default, the holder of the portfolio of floaters ends up with a short position in the riskfree floater, which translates into a liability of $\$ 1$,

\footnotetext{
${ }^{3}$ Hull and White (2001) describe a model-based pricing framework that explicitly allows for the effect of courterparty risk in the pricing of credit default swaps.

${ }^{4}$ These assumptions can be relaxed and the basic results would still hold.
} 
given that the floater is valued at par on its coupon payment dates. The protection seller in the CDS is liable for the CDS payoff, which is also worth $\$ 1$. Thus, when there is a default, both portfolios have the same payoff. ${ }^{5}$ Furthermore, neither portfolio required a cash outlay when they were set up: The proceeds of the short sale of the riskless floater were used to finance the purchase of the risky floater, and it costs nothing to enter into a vanilla CDS. As a result, in the absence of arbitrage, it must be the case that the cash flows of the two portfolios when there is no default must also be the same, $P=S$. Thus, under the conditions set out above, the spread that applies to a CDS written on a given corporation is the same as the risk spread associated with a par floater issued by that corporation.

The above example made an important point, highlighting the tight correspondence between the CDS spread for a given reference entity and the borrowing costs facing that entity. However, I am still missing several important aspects of reality. For instance, I have thus far ignored the fact that, for a leveraged investor, the first portfolio has to be funded on the balance sheet, whereas the second does not. I turn now to a slightly more realistic example that addresses this issue.

Example 2: Using the same notation and assumptions of example 1, consider the following two scenarios:

- The investor finances the purchase of the risky floater, by repoing it out, paying the repo rate $R^{f}+F$. (Alternatively, we can think of $R^{f}+F$ as the rate at which the investor can obtain financing for the portfolio.) Assuming no default by the issuer of the risky floater, the investor

\footnotetext{
${ }^{5}$ Note that, with time varying interest rates, the static replication argument outlined above would generally fail if, instead of using floating-rate notes to replicate the CDS cash flows, I had used fixed-rate notes. This occurs because a fixed-rate note is not generally valued at par after it is issued and thus the liability of the short seller in the event of default could well be different from $\$ 1$.
} 
receives $R^{f}+S$ every period and pays out $R^{f}+F$ to its repo counterparty. In the event of default, the risky floater becomes worthless, and the investor ends up owing $\$ 1$ to its repo counterparty. To sum up, the investor's cash flows are: $S-F$ (no default) and $-\$ 1$ (default).

- An investor sells $\$ 1$ worth of protection in a CDS written on the same risky floater. The cash flows associated with such a CDS position are: $P$ (no default) and $-\$ 1$ (default).

Again, notice that neither strategy required an initial cash outlay and both have the same payoff in the event of default. Thus, in the absence of arbitrage opportunities and market frictions, it must then be the case that they have the same payoff in the absence of default, i.e., the CDS premium $P$ must be the equal to the difference between the risky floater spread $S$ and the investor's funding cost $F$.

$$
P=S-F
$$

where the above differs from the result obtained from example 1 because we are now explicitly taking into account the fact that the first portfolio has to be funded on the balance sheet of a leveraged investor whereas the CDS is an unfunded instrument.

To bring the discussion of the above examples even closer to the real world, we should note the following: Although the above approach for pricing a CDS relied on rates on par floaters issued by the reference entity, most corporate debt issued in the United States are fixed-rate liabilities. In practice, however, one can circumvent this problem by resorting to the asset swap market. In particular, the above methods hold if we (i) substitute the par floater spread, $S$, with the asset swap spread associated with the reference entity in question and (ii) redefine $R^{f}$ as a short-term LIBOR rate in order 
to conform with the quoting convention for asset swaps.

\subsection{Assessing the Static Replication Approach}

We can use observed market quotes to verify how well the data support the simple valuation relationships uncovered by the above examples. As an illustration, the four panels in Figure 3 show quotes on credit default swaps and asset swaps for four investment-grade reference entities that underlie some of the most frequently negotiated credit default swaps: Bank of America, General Motors Acceptance Corp. (GMAC), Tyco International, and Walmart, which are rated $\mathrm{A}+, \mathrm{A}, \mathrm{A}-$, and $\mathrm{AA}$ by Standard and Poors, respectively.

CDS and asset swap spreads for Bank of America and GMAC do line up closely and are thus consistent with the results of the static replication replication approach. In contrast, the CDS spreads for Tyco and Walmart are substantially above what would be suggested by the asset swap market, displaying what market participants call "positive bias." The divergence between CDS and asset swap spreads for these reference entities highlights the role that market segmentation and idiosyncratic supply and demand factors still play in the developing CDS market. For instance, the substantial positive bias associated with Tyco is largely tied to strong demand by convertible bond investors for buying protection against Tyco: Tyco has issued substantial amounts of convertible debt in recent months, but the investors who have bought such bonds have focused primarily on the cheapness of embedded call option on Tyco's stock, while using the CDS market to shed the credit risk associated with Tyco. In addition, administrative and legal costs are also factored into CDS spreads in practice, and even CDSs for reference entities that borrow at sub-LIBOR rates, such as Walmart, tend to be slightly positive. Another factor that contributes to positive bias is the fact that participation in the CDS market is limited either by investors' lack of 
familiarity with credit derivatives or, as noted above, by legal restrictions and internal investment policies of certain institutional investors. In addition, for some reference entities, a liquidity premium on CDSs, reflecting the poorer liquidity of the CDS market relative to the cash (corporate bond) market for those entities, may also be a factor leading to positive bias.

\subsection{Using Credit Models to Price a CDS}

Under some circumstances, static replication techniques may prove impracticable. For instance, one might be interested in buying or selling protection against a reference entity that has no actively traded marketable debt outstanding. Credit risk models are an alternative tool for pricing credit default swaps and, especially, more complicated credit derivatives. I outline below the basic steps that make up the model-based approach to pricing a CDS.

As before, we start out with the observation that pricing a default swap means determining the premium or "spread" $p$ that will be paid periodically by the protection buyer. Let $R$ denote the recovery rate associated with the reference entity and $\$ 1$ be the notional amount of the CDS. Taking $p$ initially as given, we first compute the expected present values of the "premium" and "protection" legs of a contract that matures at a future date $T$.

To value the premium leg, we note that it is equivalent to a security that pays $p$ per period until either a default event occurs or the CDS reaches its maturity, whichever is earlier. Let $E P V$ (premium) denote the expected present value of such payments. To value the protection leg, we note that it is equivalent to a contingent claim that pays $(1-R)$ if the reference entity defaults before $T$. Let $E P V$ (protection) denote the expected present value of such a payment. Thus, the value of the CDS spread, $p$, is such that

$$
E P V(\text { premium })=E P V(\text { protection })
$$


where the expected present values in the above expression are derived from theoretical models that incorporate specific assumptions about the behavior of market interest rates and default rates in order to generate a probability distribution function for default times. Appendix A provides a simple example of such a modeling framework. Other examples include the work of Hull and White (2000, 2001).

\section{The Potential for Synthetic Riskless Assets}

In theory, market participants could combine holdings of risky assets with protection bought in the credit derivatives market to financially engineer an "asset" that, similar to U.S. Treasury securities, is essentially free from default risk. Going back to examples 1 and 2, consider an investor who buys a risky floater issued by XYZ Corp. and simultaneously purchases protection in a CDS. Such an investor is then fully insured against the possibility of default by XYZ Corp., provided the protection seller is able to make good on its commitment in the credit default swap. Indeed, in the absence of counterparty credit risk, the investor is effectively left with a synthetic riskless floater. In practice, however, the synthetic floater is not quite riskless in that the investor still has some exposure to both replacement risk and a simultaneous default by the protection seller and XYZ Corp. Of course, the use of collateral agreements helps mitigate concerns about counterparty credit risk, but posting collateral is expensive, and amounts pledged typically cover less than the total net exposure between counterparties. ${ }^{6}$

Synthetic collateralized debt obligations (CDOs) can also be used to gen-

\footnotetext{
${ }^{6} \mathrm{~A}$ common practice in the interdealer market is for market participants to call for additional collateral after their marked-to-market exposure to a particular counterparty has risen beyond a previously agreed upon threshold level.
} 
erate close substitutes to the credit risk characteristics of Treasuries. As noted above, portfolio default swaps can be used to direct the cash flow of a synthetic CDO to various tranches, with the most senior tranches being virtually free from default risk. As with traditional CDOs, the various tranches of a synthetic CDO are formally rated by the leading credit rating agencies: For instance, in its simplest form, a synthetic CDO may have three tranches, an "equity" tranche, rated below BBB, a "mezzanine" tranche, rated BBB, and a "senior" tranche rated AAA. An increasingly common variation on this arrangement, however, is for the senior tranche to be divided up further to create what is commonly called a "super senior" tranche, which benefits from the subordination of the senior tranche and thus has "better-than-AAA" risk. In particular, for the super senior tranche to sustain a default-related loss, the magnitude of defaults in the underlying portfolio would have to be such as to engulf the entire AAA-rated senior tranche, which is a very remote risk. Nonetheless, while the synthetic CDO market has grown rapidly in recent years, it still makes up less than twenty percent of the notional amount outstanding in the global credit derivatives market. In addition, the use of synthetic CDOs has been mainly motivated by the needs of commercial banks to free up regulatory capital, rather than to offer investors an alternative to the safety of U.S. Treasury securities, and indeed, U.S. banks tend to retain the super senior tranches of synthetic CDOs in their balance sheets.

On the whole, while it is conceivable that financial market participants could in principle combine holdings of risky assets with collateralized default protection bought in the credit derivatives market to effect the large scale creation of synthetic private sector assets that are virtually free of default risk, the credit derivatives market is still in its formative stages and will only reach full maturity in the years to come. For instance, in addition to counterparty credit risk, an issue that currently potentially makes such 
synthetic assets less than riskfree is what some market participants have called "legal risk" (see. e.g., Tolk, 2001). This is the risk that too broad a definition of what constitutes a "credit event" (default) in the standardized credit derivatives documentation may expose investors to unintended risks, such as the risk of having to pay for a credit event that goes beyond commonly accepted definitions of default. For instance, in early 2001, Moody's Investors Services downgraded even the senior tranches of some synthetic CDOs issued in the late 1990s because of such risks.

\section{Concluding Remarks}

The credit derivatives market has experienced remarkable growth in recent years, but it is still a relatively small and young market. Nonetheless, the prospect of continued growth, greater standardization of market practices, and further improvements in mitigating counterparty credit risk in the years to come possibly point to significant benefits for the overall financial markets. In addition to efficiency gains in the pricing and distribution of credit risk, a fully mature credit derivatives market could potentially help fill a void if the U.S. Treasury securities market continues to shrink. In particular, the credit derivatives market may eventually become sufficiently developed to allow for the large scale creation of synthetic assets that are virtually free from default risk and thus help meet the demands of buy-and-hold investors who currently favor the safety of U.S. Treasury securities.

Regarding the future outlook of the credit derivatives market, several unfolding developments may play important roles. First, the market outlook will be affected by further efforts by participants to harmonize diverging views on what types of default events should be covered in the standardized contracts. Second, the provisions of the Basle II Accord on credit derivatives 
are still being negotiated, and they may affect the way commercial banks use credit derivatives. Third, current market trends suggest increased participation of non-banks in the market and the growing use of more complex credit derivatives in portfolio risk management. 


\section{References}

British Bankers' Association, 2000, Credit Derivatives Report 1999/2000.

Hull, J., and A. White, 2000, "Valuing Credit Default Swaps I: No Counterparty Default Risk," Journal of Derivatives 8, 29-40.

Hull, J., and A. White, 2001, "Valuing Credit Default Swaps II: Modeling Default Correlations," Journal of Derivatives, forthcoming.

Jarrow and Turnbull, 1995, "Pricing derivatives on financial securities subject to credit risk," Journal of Finance 50, 53-86.

O'Kane, D., 2001, "Credit Derivatives Explained: Market, Products, and Regulations," Lehman Brothers International.

O'Kane, D., and L. Schloegl, 2001, Modeling Credit: Theory and Practice, Lehman Brothers International.

J.P. Morgan, 1999, The J.P. Morgan Guide to Credit Derivatives, London: Risk Publications.

Rule, David, 2001, "The Credit Derivatives Market: Its development and possible implications for financial stability," Financial Stability Review, Bank of England, (June), 117-140.

Tavakoli, J., 1998, Credit Derivatives: A guide to instruments and applications, New York: Wiley.

Tolk, J., 2001, "Understanding the Risks in Credit Default Swaps," Moody's Investors Service, March 16. 


\section{Appendix: Pricing a Credit Default Swap}

Drawing from the work of O'Kane and Schloegl (2001), I outline below a simple framework for pricing a credit default swap. Following the modeling methodology initiated by by Jarrow and Turnbull (1995), we assume that defaults are exogenous events that can be modeled as a counting process. In particular, let $N(t)$ denote the number of events that have occurred up to time t, where an event corresponds to a jump in the value of $N$. The first time of jumping is defined as a the time of default, and thus, for $N(0)=0$, we can write the time of default, $\tau$, as

$$
\tau=\min \{t \geq 0 \mid N(t) \geq 1\}
$$

The default counting process can be modeled as a Poisson process, whose stochastic behavior is determined by its hazard rate, $\lambda(t)$. The conditional instantaneous probability of default at time $t$, or the probability of default between $t$ and $t+d t$ assuming no default has occurred up until $t$, is given by

$$
P(\tau \leq t+d t \mid \tau>t)=\lambda(t) d t
$$

Integrating the above equation, we can compute the time-t probability that no default will occur before an arbitrary future time $T$ :

$$
P(\tau>T)=e^{-\int_{t}^{T} \lambda(s) d s}
$$

Pricing defaultable claims. Suppose we want to price a defaultable claim that pays $X(T)$ at time $\mathrm{T}$ if no default has occurred by then and zero otherwise. Under the risk-neutral valuation, and using the money market account $\beta(T) \equiv e^{\int_{t}^{T} r(u) d u}$ as the numeraire - where $r(t)$ is the instantaneous riskfree 
interest rate - the time-t price of such a claim is

$$
C^{d}(t)=E_{t}^{Q}\left[\frac{X(T)}{\beta(T)} l_{\{\tau>T\}}\right]
$$

where $E_{t}^{Q}[$.$] is the time-t expectation under the risk-neutral measure, and$ $l_{\{\tau>T\}}$ is an indicator variable, set to 1 if default has not occurred by time $\mathrm{T}$ and zero otherwise. Assuming that $\frac{X(T)}{\beta(T)}$ and the credit process - denoted by $l_{\{\tau>T\}}$-are independent, we can write

$$
C^{d}(t)=E_{t}^{Q}\left[\frac{X(T)}{\beta(T)}\right] P(\tau>T)
$$

where we used the fact that $l_{\{\tau>T\}}$ is 1 with probability $P(\tau>T)$ and zero otherwise, and so its expected value is $P(\tau>T)$.

Note that, in the absence of default risk, $P(\tau>T)$ would be 1 and $X(T) / \beta(T)$ would be the payoff of a default-free claim. The expected present value of such a payoff would be $C(t)=E_{t}^{Q}\left[\frac{X(T)}{\beta(T)}\right]$, and thus we can write the pricing equation for the defaultable claim:

$$
C^{d}(t)=C(t) P(\tau>T)
$$

Using the above expression, it is then straightforward to price a defaultable bond; its price is given by the price of a default-free bond multiplied by the probability of no default through time $\mathrm{T}$, which we take to be the maturity of the bond:

$$
B_{0}^{d}(t, T)=B(t, T) P(\tau>T)
$$

Assuming that the riskless rate is constant leads to $B(t, T)=e^{-r(T-t)}$. In 
addition, given equation (5), and assuming that $\lambda(t)$ is time-invariant:

$$
B_{0}^{d}(t, T)=e^{-(r+\lambda)(T-t)}
$$

Therefore, with zero recovery, the spread between the yield on a defaultable bond over that on a default-free bond is given the hazard rate.

Allowing for recovery. We can modify the pricing model to allow for non-zero recovery rates. Consider a contingent claim that pays $Y(\tau)$ at the time of default, if a default does occur before a given time $T$, and zero otherwise. Because the default time, $\tau$, is stochastic, we need to derive its probability density, $P(s<\tau \leq s+d s)$, in order to be able to price such a claim. Using the definition of a conditional probability density, we have that, for $s \geq t$,

$$
P(s<\tau \leq s+d s)=P(\tau \leq s+d s \mid \tau>s) P(\tau>s)=\lambda(s) e^{-\int_{t}^{s} \lambda(u) d u} d s
$$

The above equation simply says that the time-t probability of a default occurring in some future time interval $[s, s+d s]$ is equal to the probability of surviving through time $s, P(\tau>s)$, times the conditional probability of default in the next time interval.

Let $D(t)$ be the time-t price of the default contingent claim. Again using the bank account as the numeraire, we can write

$$
D(t)=\int_{t}^{T} E_{t}^{Q}\left[\frac{Y(s)}{\beta(s)}\right] \lambda(s) e^{-\int_{t}^{s} \lambda(u) d u} d s
$$

If we now assume that the payoff $Y(\tau)$ is determinist, say $Y(\tau)=1$, and recalling that $E_{t}^{Q}\left[\beta(\tau)^{-1}\right]=E_{t}^{Q}\left[e^{\int_{t}^{\tau} r(u) d u}\right]$ is the time-t price of a default-free bond with maturity $\tau$, we can write

$$
D(t)=\int_{t}^{T} B(t, s) \lambda e^{-\lambda(s-t)} d s=\frac{\lambda}{r+\lambda}\left(1-e^{-(r+\lambda)(T-t)}\right)
$$


where above we again assumed that $\lambda(t)$ and $r$ are time-invariant.

We can now price a defaultable bond with face value $\$ 1$ that pays a recovery rate $R$ - expressed as a percentage of the bond's face value - in the event of default. We can think of such a bond as a portfolio composed by a defaultable bond that pays no recovery and a contingent claim that pays $R$ in the event of default. Given equations (10) and (13), the price of such a bond is

$$
B^{d}(t, T)=B_{0}^{d}(t, T)+R D(t)=e^{-(y+\lambda)(T-t)}+R \frac{\lambda}{r+\lambda}\left(1-e^{-(r+\lambda)(T-t)}\right)
$$

The above expression can be used for determining the "fair value" of, say, a corporate bond. In practice though, recovery rates are a major problem in the credit market because of the significant uncertainty surrounding actual recovery rates.

Pricing a credit default swap. Pricing a default swap means determining the premium or "spread" $p$ that will be paid periodically by the protection buyer. Taking $p$ initially as given, we first compute the time-t value of the "premium" and "protection" legs of a contract with maturity at T. For simplicity assume that the premium is paid continuously and that the riskless and hazard rates are constants. The present value of the premium leg is

$$
\eta(t)=\int_{t}^{T} p e^{-(r+\lambda)(s-t)} d s=\frac{p}{r+\lambda}\left(1-e^{-(r+\lambda)(T-t)}\right)
$$

Notice above that, as in equation (10), the premium stream is discounted at the risky rate $r+\lambda$, reflecting the uncertainty surrounding the default event.

To value the protection leg, we note that it is equivalent to a contingent claim that pays $(1-R)$ in the event of default before $\mathrm{T}$. The value of such as claim is given by equation (13). Letting $\theta(t)$ denote the value of the 
protection leg, we can write

$$
\theta(t)=\frac{\lambda(1-R)}{r+\lambda}\left(1-e^{-(r+\lambda)(T-t)}\right)
$$

A default swap typically has zero market value when it is set up, and thus pricing such a contract is equivalent to finding the value of $p$ that makes the two legs of the swap have equal value. This is given by

$$
p=\lambda(1-R)
$$

which is approximately the same as the corporate yield spread derived in equation (14). Note that, by postulating a given recovery rate, we can use the above expression and observable default swap spreads to derive the marketimplied probability of default by the company underlying a default swap. In particular, assuming that $\lambda$ is constant and using equation (5), we can write the market-implied probability of default between now, time $t$, and some future date $T$ as

$$
\hat{P}(\tau<T)=1-e^{-\hat{\lambda}(T-t)}
$$

where $\hat{\lambda} \equiv p /(1-R)$ is the market-implied hazard rate.

Extensions. The above setup made several restrictive assumptions, such as continuously paid premiums, constant interest rates and intensity, and zero coupons. All of these assumptions can be relaxed to make the pricing exercise closer to reality. 
Figure 1

Notional Amounts of Credit Derivatives at U.S. Commercial Banks

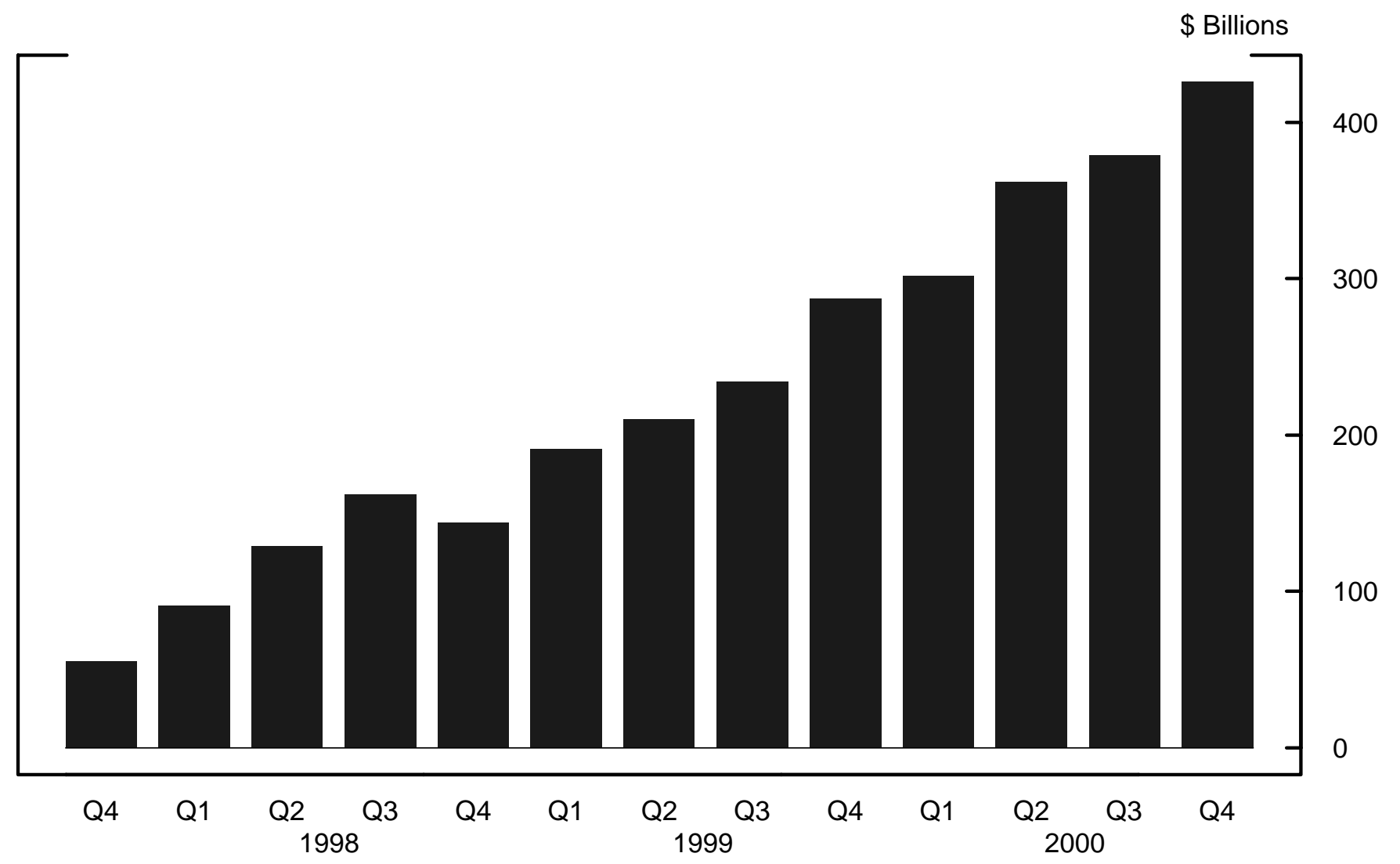

Source: Federal Reserve, Call Reports 
Figure 2

\section{Selected Five-Year Credit Default Swap Spreads}

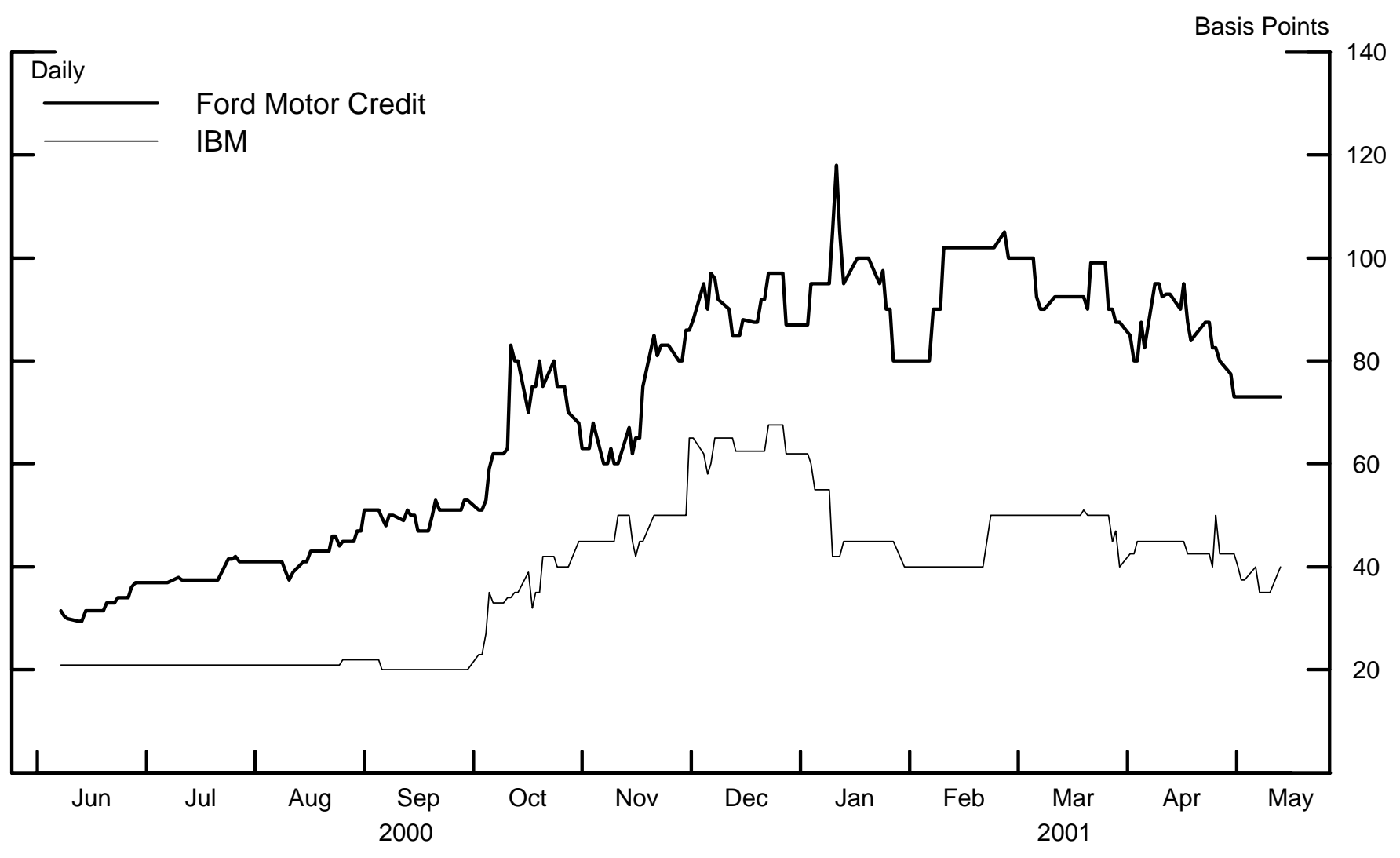

Source: JP Morgan Chase 
Figure 3

\section{An Informal Test of the Static Replication Approach}

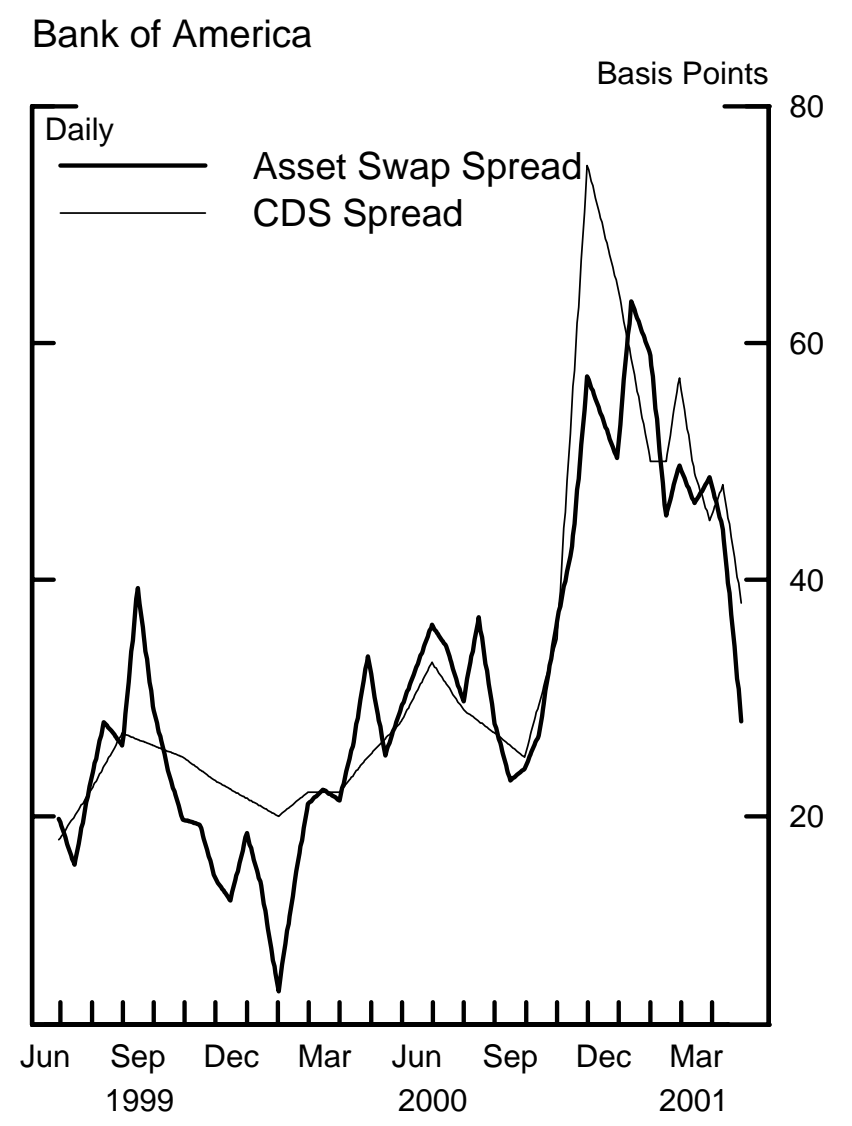

General Motors Acceptance Corp.

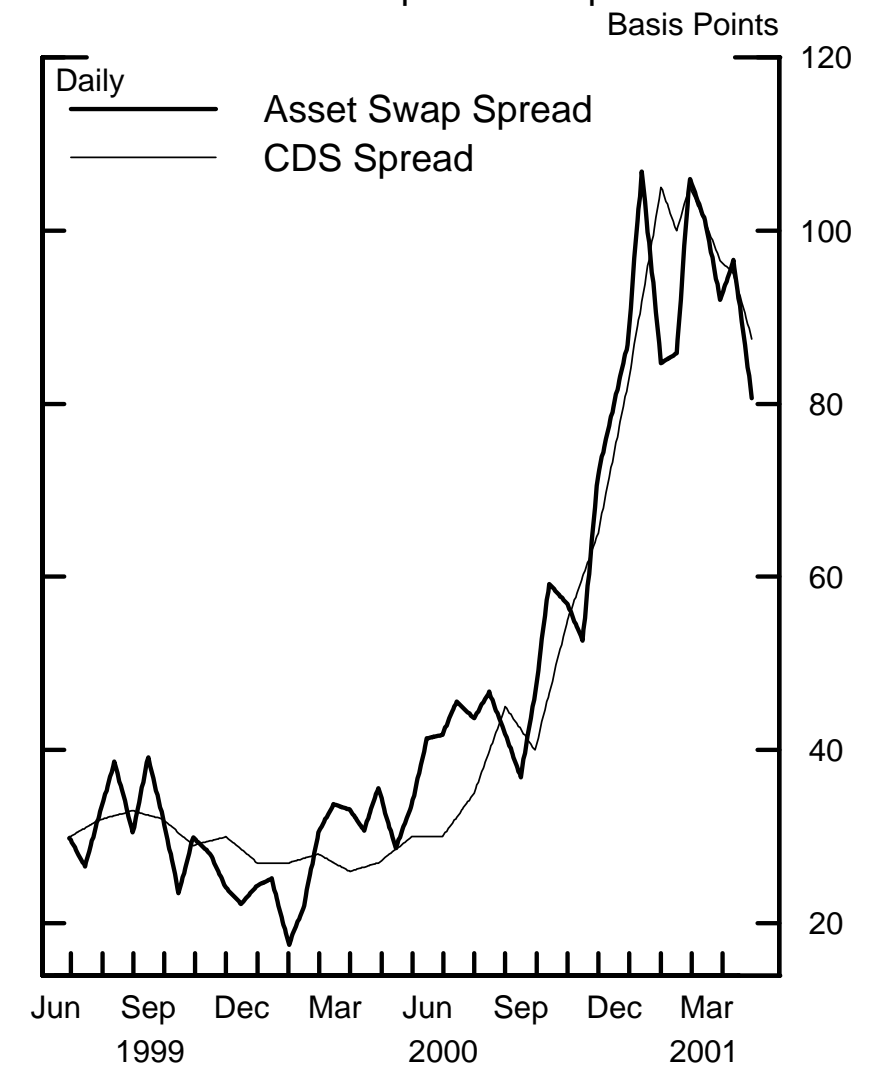

TYCO

Walmart
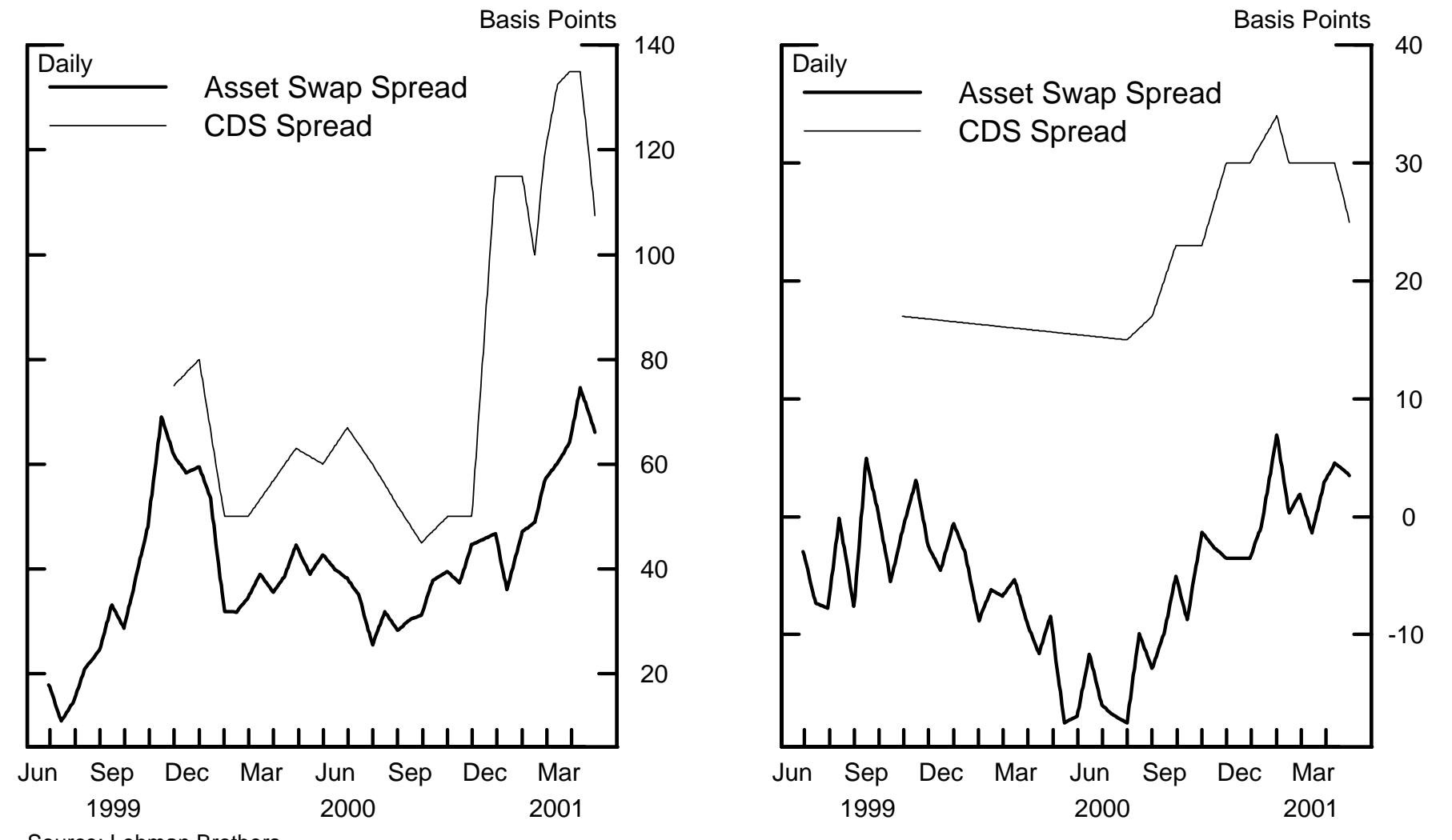

Note. Quotes shown are for contracts maturing in five years. 